\title{
Hydrophobic Aib/Ala peptides solubilize in water through formation of supramolecular assemblies
}

\author{
Edoardo Longo, Marco Crisma, Fernando Formaggio, Claudio Toniolo and Alessandro Moretto \\ We recently reported that a series of Aib/Ala-containing peptides, lacking any charge or polar group, are soluble in water. In this \\ work, we present evidence of the formation of self-assembled structures in water, likewise responsible for the unexpected \\ solubility properties. These peptide aggregates are spherical, with diameters up to $100 \mathrm{~nm}$. They can also incorporate other \\ molecular structures of relevant size, such as Au nanoparticles. More experiments are needed to understand the precise nature \\ of these supramolecular structures. However, such systems may widen the number of applications currently accessible to \\ self-assembled aggregates in the fields of biomedicine and materials science.
}

Polymer Journal (2013) 45, 516-522; doi:10.1038/pj.2013.24; published online 6 March 2013

Keywords: $\alpha$-aminoisobutyric acid; helical peptides; self-assembled peptides; X-ray diffraction

\section{INTRODUCTION}

During the solution syntheses of peptides containing alternating Ala and Aib ( $\alpha$-aminoisobutyric acid) stretches, we observed unusually low yields. After a careful inspection of all synthetic steps, we discovered that much of the product was lost in the purification procedures as, unexpectedly, these peptides are soluble in water. ${ }^{1,2} \mathrm{To}$ the best of our knowledge, this is the first example of a class of $\mathrm{N}$ - and C-terminally protected, hydrophobic peptides able to dissolve in water. This finding is even more surprising in view of the absence of any residue having a charged (for example, Lys and Asp) or a polar (for example, Ser and Thr) side chain. The explanation of such a behavior is not straightforward. Therefore, we started a series of experiments aimed at explaining the observed hydrosolubility. The preliminary results of our efforts, reported in this work, focus on the undecapeptide $\mathrm{Z}$-(L-Ala $)_{3}$-(Aib-L-Ala $)_{4}-\mathrm{OMe},{ }^{1}$ where $\mathrm{Z}$ is benzyloxycarbonyl and OMe is methoxy.

Interestingly, these Ala/Aib peptides maintain in water ${ }^{2}$ the same helical conformations they display in organic solvents. ${ }^{3-7}$ Thus, one cannot ascribe their solubility in water to a conformational change, according to which, for instance, the polar peptide moieties would be exposed to the solvent and not any longer engaged in intramolecular H-bonds. A different mechanism has definitely to be involved. In a $3_{10^{-}}$or $\alpha$-helical peptide two or three, respectively, amide carbonyls at the $\mathrm{C}$ terminus are not part of the intramolecular H-bonding network. The same situation applies to the first two or three amide $\mathrm{NHs}$ at the $\mathrm{N}$ terminus. Taking into account these observations, we hypothesized that aggregates of helical peptides would form, in which the $\mathrm{N}$ - and/or C-terminal segments are located on the external surface, in contact with water molecules, whereas the hydrophobic sections of the peptides are embedded in the aggregate.

\section{EXPERIMENTAL PROCEDURE}

\section{Synthesis}

The terminally protected undecapeptide Z-(L-Ala $)_{3}$-(Aib-L-Ala $)_{4}-\mathrm{OMe}$ was prepared by solution synthesis, according to the procedures previously described. ${ }^{2}$ Analytical data: m.p. $135-137^{\circ} \mathrm{C} ;[\alpha]_{\mathrm{D}}{ }^{20}$ : $-10.1(c=0.4, \mathrm{MeOH})$; infrared (KBr): 3330, 1740, 1662 and $1531 \mathrm{~cm}^{-1} ;{ }^{1} \mathrm{H}$ NMR $\left(200 \mathrm{MHz}, \mathrm{CDCl}_{3}\right)$ : $\delta$ 8.10-7.20 (6s and 4d, 10H, 4 Aib and $6 \mathrm{Ala} \mathrm{NH}$ ), 7.36 ( $\mathrm{m}, 5 \mathrm{H}$ and phenyl $\mathrm{CH}), 7.16\left(\mathrm{~d}, 1 \mathrm{H}\right.$ and Ala NH), $5.18\left(\mathrm{~s}, 2 \mathrm{H}\right.$ and $\left.\mathrm{Z} \mathrm{CH}_{2}\right), 4.54-4.10(\mathrm{~m}, 7 \mathrm{H}$ and 7 Ala $\alpha-\mathrm{CH}), 3.68\left(\mathrm{~s}, 3 \mathrm{H}\right.$ and $\left.-\mathrm{OMe} \mathrm{CH}_{3}\right), 1.61-1.20(\mathrm{~m}, 45 \mathrm{H}, 8 \mathrm{Aib}$ and 7 Ala $\beta-\mathrm{CH}_{3}$ ); electrospray ionization mass spectrometry $\mathrm{m} / z$ : calculated for $\mathrm{C}_{46} \mathrm{H}_{73} \mathrm{~N}_{11} \mathrm{O}_{14}$ 1004.16, found 1004.11. Z-(L-Ala $)_{3}$-(Aib-L-Ala) $)_{4}-\mathrm{OH}$ was obtained by treatment of its methyl ester precursor with a methanolic solution of $\mathrm{LiOH}$, followed by protonation to - $\mathrm{COOH}$ with dilute $\mathrm{HCl}$ : infrared $(\mathrm{KBr})$ : 3323,1663 and $1539 \mathrm{~cm}^{-1}$; electrospray ionization mass spectrometry $\mathrm{m} / \mathrm{z}$ : calculated for $\mathrm{C}_{45} \mathrm{H}_{71} \mathrm{~N}_{11} \mathrm{O}_{14}$ 990.13, found 990.10. The synthesis of the $\mathrm{Au}$ nanoparticles (AuNps11) used for the encapsulation experiments was previously reported. ${ }^{1}$ AuNps11 are Au nanoparticles coated with the same peptide segment, -(L-Ala $)_{3}$-(Aib-L-Ala $)_{4^{-}}$, responsible for the formation in water of the large aggregates described in this work.

\section{Electronic circular dichroism}

The electronic circular dichroism (CD) spectra were obtained on a Jasco model J-715 spectropolarimeter (Jasco, Easton, MD, USA). A cylindrical fused Hellma quartz cell of $0.1 \mathrm{~mm}$ path length was employed. The data are expressed in terms of $[\theta]_{\mathrm{T}}$, the total molar ellipticity $\left(\operatorname{deg} \times \mathrm{cm}^{2} \times \mathrm{dmol}^{-1}\right)$. The solvent used was MilliQ pH 7 water (Merck, Billerica, MA, USA).

\section{Dynamic light scattering (DLS) analysis}

DLS measurements were performed with a Malvern Zetasizer NanoS instrument (Worcestershire, UK) equipped with a thermostatted cell holder and an Ar laser operating at $633 \mathrm{~nm}$. Hydrodynamic particle diameters were obtained 
from cumulant or distribution fit of the autocorrelation functions collected at the $178^{\circ}$ scattering angle. Size measurements were performed at $25^{\circ} \mathrm{C}$ in water.

\section{Transmission electron microscopy}

The samples, prepared immediately before use by dilution (100 times) of the peptide aggregate solutions with water and vortex, were analyzed on a Jeol 300PX instrument (Jeol, Tokyo, Japan). A glow-discharged carbon-coated grid was floated on a small drop of the solution and excess was removed by hardened Whatman filter paper no. 50. The grid was then floated on $2 \%$ uranyl acetate solution for $10 \mathrm{~s}$, and the excess was removed by hardened Whatman filter paper no. 50 .

\section{Atomic force microscopy}

Atomic force microscopy images were taken using a Park Autoprobe CP instrument (Park, Suwon, Korea) operating in contact mode in air. Samples were prepared, immediately before analysis, by dilution of the peptide aggregate solutions with water and vortex. The topographies were acquired under environment conditions. The scan rate was $1.0 \mathrm{~Hz}$, and the force set point was the lowest to improve resolution, and at the same time minimizing damage to the samples. Surface morphological investigations were performed on as-prepared samples $\left(\sim 2 \times 2 \mathrm{~cm}^{2}\right)$ obtained by drop casting the aggregate solutions at different concentrations on a mica substrate.

\section{X-ray diffraction}

Single crystals of $\mathrm{Z}$-(L-Ala) $)_{3}$ (Aib-L-Ala) ${ }_{4}-\mathrm{OH}$ were grown by slow evaporation from an isopropanol solution. X-ray diffraction data were collected with an Agilent Technologies (Yarnton, UK) Gemini E four-circle kappa diffractometer equipped with a $92 \mathrm{~mm}$ EOS charge-coupled device detector, using graphite monochromated $\mathrm{Cu} \mathrm{K} \alpha$ radiation $(\lambda=1.54178 \AA)$. Data collection and reduction were performed with the CrysAlisPro software (version 1.171.35.11; Agilent Technologies). A semi-empirical absorption correction based on the multiscan technique using spherical harmonics, implemented in SCALE3 ABSPACK scaling algorithm, was applied.

The structure was solved by direct methods of the SIR 2002 program. ${ }^{8}$ The asymmetric unit is composed of one peptide molecule and three cocrystallized water molecules. Refinement was carried out by full-matrix least-squares procedures on $F^{2}$, using all data, by application of the SHELXL-97 program, ${ }^{9}$ with all anisotropic non-H-atoms. $\mathrm{H}$-atoms of the peptide molecule were calculated at idealized positions and refined using a riding model. The positions of the $\mathrm{H}$-atoms of the cocrystallized water molecules were recovered from a difference Fourier map and they were not refined. Relevant crystal data and structure-refinement parameters are listed in Table 1. CCDC 908157contains the supplementary crystallographic data for this paper. These data can be obtained from The Cambridge Crystallographic Data Centre via www.ccdc.cam.ac.uk/data_request/cif.

\section{RESULTS AND DISCUSSION}

\section{Peptide conformation}

The electronic CD spectra of Z-(L-Ala $)_{3}-(\text { Aib-L-Ala })_{4}-\mathrm{OMe}$ and its C-terminal free analog Z-(L-Ala) $)_{3}-(\text { Aib-L-Ala })_{4}-\mathrm{OH}$ in water at $1 \mathrm{~mm}$ peptide concentration are reported in Figure 1 (curves $\mathbf{A}$ and $\mathbf{B}$ ). Although slightly diverging, the two spectra are indicative of $\alpha$-helical structures, as the ratios of the ellipticities between the two negative Cotton effects at about 222 and $205 \mathrm{~nm}$ are 0.74 for Z-(L-Ala) $3^{-}$ (Aib-L-Ala) $)_{4}$-OMe and 0.91 for Z-(L-Ala) ${ }_{3}$ (Aib-L-Ala) $)_{4}-\mathrm{OH} \cdot{ }^{10,11}$ In $\mathrm{MeOH}$, at the same concentration, Z-(L-Ala) ${ }_{3}$-(Aib-L-Ala) ${ }_{4}$-OMe does retain, and even improves, its $\alpha$-helical character (curve $\mathrm{C}$ ). Under these conditions, the peptide is believed to be in a monomeric state. We also recorded the CD spectrum (curve D) of Z-(L-Ala) $3^{-}$

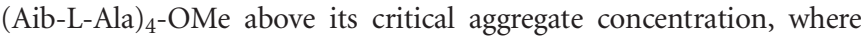
large spherical aggregates form (see below). To this aim, a $20 \mathrm{~mm}$ peptide solution in water was prepared by sonication. For a reliable CD measurement, the solution had to be diluted to about $1 \mathrm{~mm}$.
Table 1 Crystal data and structure refinement for Z-(L-Ala) $)_{3}^{-}$ (Aib-L-Ala) ${ }_{4}-\mathrm{OH}$ trihydrate

\begin{tabular}{|c|c|}
\hline Empirical formula & $\mathrm{C}_{45} \mathrm{H}_{77} \mathrm{~N}_{11} \mathrm{O}_{17}$ \\
\hline Formula weight & 1044.18 \\
\hline Temperature & $293(2) \mathrm{K}$ \\
\hline Wavelength & $1.54178 \AA$ \\
\hline Crystal system & Monoclinic \\
\hline Space group & $\mathrm{C} 2$ \\
\hline Unit cell dimensions & $\begin{array}{c}a=33.2617(13) \AA ; \alpha=90^{\circ} \\
b=8.4156(2) \AA ; \beta=124.813(6)^{\circ} \\
c=24.4073(10) \AA ; \gamma=90^{\circ}\end{array}$ \\
\hline Volume & $5609.2(3) \AA^{3}$ \\
\hline$Z$ & 4 \\
\hline Density (calculated) & $1.236 \mathrm{mg} \mathrm{m}^{-3}$ \\
\hline Absorption coefficient & $0.796 \mathrm{~mm}^{-1}$ \\
\hline$F(000)$ & 2240 \\
\hline Crystal size & $0.50 \times 0.28 \times 0.04 \mathrm{~mm}^{3}$ \\
\hline$\theta$ Range for data collection & $2.68-61.02^{\circ}$ \\
\hline Index ranges & $-37 \leqslant h \leqslant 37,-9 \leqslant k \leqslant 8,-27 \leqslant 1 \leqslant 27$ \\
\hline Reflections collected & 22711 \\
\hline Independent reflections & $7604(R($ int $)=0.0342)$ \\
\hline Completeness to $\theta=61.02^{\circ}$ & $99.4 \%$ \\
\hline Absorption correction & Semi-empirical from equivalents \\
\hline Maximum and minimum transmission & 1.00000 and 0.60880 \\
\hline Refinement method & Full-matrix least-squares on $F^{2}$ \\
\hline Data/restraints/parameters & $7604 / 1 / 658$ \\
\hline Goodness-of-fit on $F^{2}$ & 0.993 \\
\hline Final $R$ indices $(I>2 \sigma(I))$ & $R_{1}=0.0413, w R_{2}=0.1057$ \\
\hline$R$ indices (all data) & $R_{1}=0.0465, w R_{2}=0.1102$ \\
\hline Absolute structure parameter & $-0.12(17)$ \\
\hline Largest difference peak and hole & 0.166 and $-0.159 \mathrm{e}^{-3}$ \\
\hline
\end{tabular}

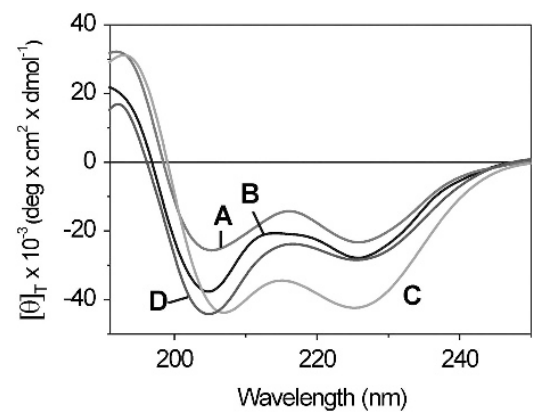

Figure 1 Far-UV electronic circular dichroism (ECD) spectra, recorded at $20{ }^{\circ} \mathrm{C}$, of $\mathrm{Z}-(\mathrm{L}-\mathrm{Ala})_{3}-(\mathrm{Aib}-\mathrm{L}-\mathrm{Ala})_{4}-\mathrm{OH}$ in water $(\mathbf{A})$ and $\mathrm{Z}-(\mathrm{L}-\mathrm{Ala})_{3}-(\mathrm{Aib}-\mathrm{L}-\mathrm{Ala})_{4}-$ $\mathrm{OMe}$ in water $(\mathbf{B})$ and methanol $(\mathbf{C})$, at $1 \mathrm{~mm}$ peptide concentration. Far-UV ECD spectrum of Z-(L-Ala) $)_{3}-(\text { Aib-L-Ala })_{4}-O M e$ in water (D) above the critical aggregate concentration. A full color version of this figure is available at Polymer Journal online.

However, the persistence of the aggregates was confirmed by transmission electron microscopy (TEM) measurements.

The $\mathrm{CD}$ patterns of $\mathrm{Z}$-(L-Ala $)_{3}$-(Aib-L-Ala $)_{4}-\mathrm{OMe}$ in the monomeric and aggregated states (curves $\mathbf{B}$ and $\mathbf{D}$, respectively) are quite similar, thus implying that the peptide maintains its helical conformation in the self-assembled state. This finding may not be surprising in view of the known conformational stability of peptide helices heavily based on $C^{\alpha}$-tetrasubstituted $\alpha$-amino acids. Indeed, the $\alpha$-helical structure of $\mathrm{Z}$-( $\mathrm{L}$-Ala $)_{3}$-(Aib-L-Ala $)_{4}$-OMe is preserved in methanol as well (curve $\mathbf{C}$ ). 


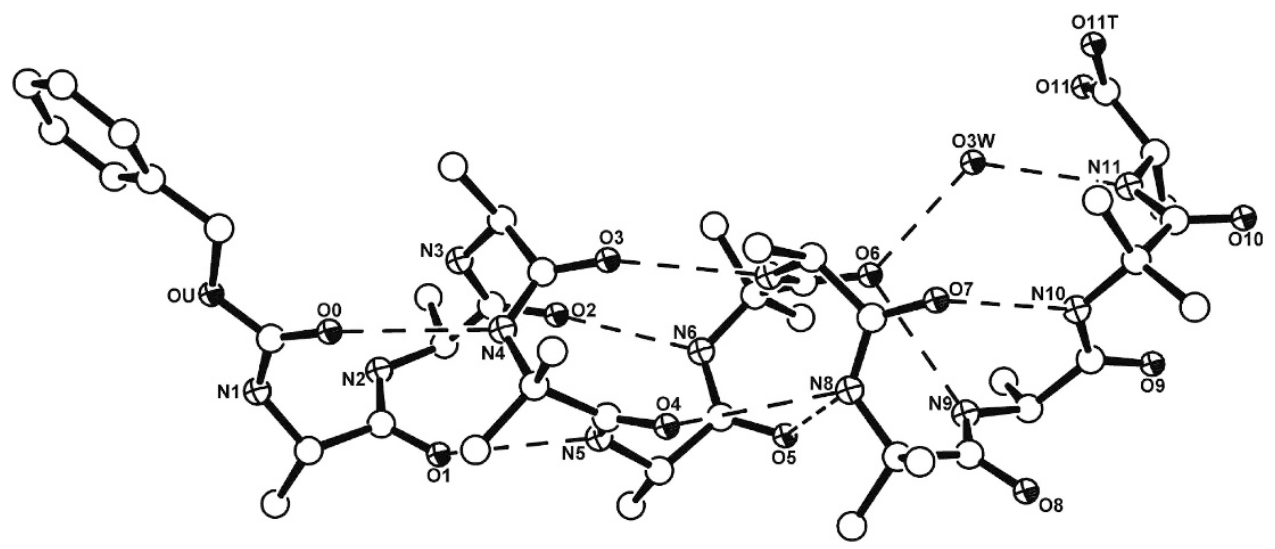

Figure 2 X-ray diffraction structure of Z-(Ala $)_{3}-(\mathrm{Aib}-\mathrm{L}-\mathrm{Ala})_{4}-\mathrm{OH}$. Only one $(\mathrm{O} 3 \mathrm{~W})$ of the three cocrystallized water molecules is shown. The intramolecular $\mathrm{H}$-bonds are represented by dashed lines.

Table 2 Selected torsion angles $\left({ }^{\circ}\right)$ for Z-(L-Ala) $)_{3}-(\text { Aib-L-Ala })_{4}-\mathrm{OH}$ trihydrate

\begin{tabular}{lrrlrr}
\hline C02-C01-C07-OU & & 148.6 (3) & CA5-C5-N6-CA6 & $\omega^{5}$ & $177.27(19)$ \\
C06-C01-C07-OU & & -32.1 (5) & C5-N6-CA6-C6 & $\varphi^{6}$ & $-55.5(3)$ \\
C01-C07-OU-C0 & & $171.1(3)$ & N6-CA6-C6-N7 & $\psi^{6}$ & $-45.0(3)$ \\
C07-OU-C0-N1 & & $-174.5(3)$ & CA6-C6-N7-CA7 & $\omega^{6}$ & $-176.1(2)$ \\
OU-C0-N1-CA1 & & $-172.4(2)$ & C6-N7-CA7-C7 & $\varphi^{7}$ & $-61.0(3)$ \\
C0-N1-CA1-C1 & $\varphi^{1}$ & $-64.7(3)$ & N7-CA7-C7-N8 & $\psi^{7}$ & $-41.0(3)$ \\
N1-CA1-C1-N2 & $\psi^{1}$ & $-38.8(3)$ & CA7-C7-N8-CA8 & $\omega^{7}$ & $-175.7(2)$ \\
CA1-C1-N2-CA2 & $\omega^{1}$ & $-179.2(2)$ & C7-N8-CA8-C8 & $\varphi^{8}$ & $-60.8(3)$ \\
C1-N2-CA2-C2 & $\varphi^{2}$ & $-67.9(3)$ & N8-CA8-C8-N9 & $\psi^{8}$ & $-24.4(3)$ \\
N2-CA2-C2-N3 & $\psi^{2}$ & $-42.2(4)$ & CA8-C8-N9-CA9 & $\omega^{8}$ & $179.5(3)$ \\
CA2-C2-N3-CA3 & $\omega^{2}$ & $179.4(2)$ & C8-N9-CA9-C9 & $\varphi^{9}$ & $-72.6(4)$ \\
C2-N3-CA3-C3 & $\varphi^{3}$ & $-61.1(3)$ & N9-CA9-C9-N10 & $\psi^{9}$ & $-19.3(4)$ \\
N3-CA3-C3-N4 & $\psi^{3}$ & $-44.8(3)$ & CA9-C9-N10-CA10 & $\omega^{9}$ & $177.9(3)$ \\
CA3-C3-N4-CA4 & $\omega^{3}$ & $-179.0(2)$ & C9-N10-CA10-C10 & $\varphi^{10}$ & $53.4(4)$ \\
C3-N4-CA4-C4 & $\varphi^{4}$ & $-54.1(3)$ & N10-CA10-C10-N11 & $\psi^{10}$ & $52.2(4)$ \\
N4-CA4-C4-N5 & $\psi^{4}$ & $-48.5(3)$ & CA10-C10-N11-CA11 & $\omega^{10}$ & $-175.5(3)$ \\
CA4-C4-N5-CA5 & $\omega^{4}$ & $-176.0(2)$ & C10-N11-CA11-C11 & $\varphi^{11}$ & $-151.6(3)$ \\
C4-N5-CA5-C5 & $\varphi^{5}$ & $-70.7(3)$ & N11-CA11-C11-011T & $\psi^{11}$ & $50.0(3)$ \\
N5-CA5-C5-N6 & $\psi^{5}$ & $-43.3(3)$ & & &
\end{tabular}

To get a closer look into the conformational features possibly responsible for the water solubility of our Ala/Aib peptides, we tried to grow single crystals of $\mathrm{Z}$-( $\mathrm{L}-\mathrm{Ala})_{3}$-(Aib-L-Ala) $)_{4}$-OMe. Our attempts were successful only for its closely related analog Z-(L-Ala) ${ }_{3}$ (AibL-Ala $)_{4}-\mathrm{OH}$. Its molecular conformation, as determined by singlecrystal X-ray diffraction, is illustrated in Figure 2.

Relevant torsion angles are reported in Table 2, whereas intra- and intermolecular H-bond parameters are listed in Table 3.

The conformation adopted by the undecapeptide is right-handed $\alpha$-helical for most of its length. Indeed, starting from the $\mathrm{N}$ terminus, five consecutive, $\mathrm{N}-\mathrm{H} \ldots \mathrm{O}=\mathrm{C}$ intramolecularly $\mathrm{H}$-bonded $\mathrm{C}_{13}$ structures $\left(\alpha\right.$-turns) ${ }^{12}$ are observed (Table 3 ). The H-bond donors are the $\mathrm{NH}$ groups of residues from 4 to 8 , and the acceptors are the $\mathrm{Z}$-urethane carbonyl oxygen $\mathrm{O} 0$ and the carbonyls of residues from 1 to 4 , respectively. The average values of the backbone torsion angles for residues $1-7$ are $\phi=-62.1^{\circ}, \psi=-43.4^{\circ}$, very close to those
Table 3 Hydrogen bonds for Z-(L-Ala) 3 -(Aib-L-Ala) ${ }_{4}-\mathrm{OH}$ trihydrate ( $\AA$ and ${ }^{\circ}$ )

\begin{tabular}{lcccc}
\hline D-H...A & $d(D-H)$ & $d(H \ldots A)$ & $d(D \ldots A)$ & $<(D H A)$ \\
\hline N4-H04...001 & 0.86 & 2.28 & $3.118(3)$ & 164.7 \\
N5-H05...01 & 0.86 & 2.44 & $3.260(3)$ & 159.8 \\
N6-H06...02 & 0.86 & 2.03 & $2.876(3)$ & 169.7 \\
N7-H07...03 & 0.86 & 2.09 & $2.918(2)$ & 160.9 \\
N8-H08...04 & 0.86 & 2.52 & $3.289(3)$ & 149.7 \\
N8-H08...05 & 0.86 & 2.62 & $3.156(3)$ & 121.9 \\
N9-H09...06 & 0.86 & 2.42 & $3.163(3)$ & 145.3 \\
N10-H010..07 & 0.86 & 2.21 & $3.026(3)$ & 157.7 \\
N11-H011...03W & 0.86 & 2.03 & $2.863(3)$ & 161.2 \\
O3W-H3WA...06 & 0.83 & 1.99 & $2.780(3)$ & 159.8 \\
O11T-H11T...09\#1 & 0.82 & 1.83 & $2.634(3)$ & 166.0 \\
N1-H01...010\#2 & 0.86 & 2.23 & $3.052(3)$ & 159.9 \\
N2-H02...01W\#2 & 0.86 & 2.17 & $3.011(3)$ & 167.2 \\
N3-H03...02W\#2 & 0.86 & 2.29 & $3.043(3)$ & 146.1 \\
O1W-H1WA...010 & 0.80 & 1.98 & $2.767(3)$ & 167.6 \\
O1W-H1WB...011\#3 & 0.88 & 2.01 & $2.833(4)$ & 154.9 \\
O2W-H2WA...01\#4 & 0.85 & 2.24 & $3.006(4)$ & 149.0 \\
O2W-H2WB...01W101 & 0.86 & 2.05 & $2.857(4)$ & 156.6 \\
O3W-H3WB...08\#1 & 0.90 & 2.05 & $2.930(4)$ & 165.3 \\
\hline
\end{tabular}

Symmetry transformations used to generate equivalent atoms: 1 x,y $+1, z$; \#2 $x-1 / 2, y+1 / 2, z-$ $1 ; \# 3-x+5 / 2, y-1 / 2,-z+2 ; \# 4 x+1 / 2, y+1 / 2, z+1$.

obtained from a statistical analysis of high-resolution crystal structures of $\alpha$-helical peptides $\left(\phi=-63^{\circ}, \psi=-42^{\circ}\right) .^{13}$ The N8-H group, in addition to being $\mathrm{H}$-bonded to $\mathrm{O} 4$ in a $\mathrm{C}_{13}$ structure, is also $\mathrm{H}$-bonded to $\mathrm{O} 5$, thus forming a $\mathrm{C}_{10}$ structure $(\beta \text {-turn })^{12,14}$ as well. In this three-center $\mathrm{H}$-bond arrangement, ${ }^{15}$ the $\mathrm{N} 8-\mathrm{H} \ldots \mathrm{O} 4$ interaction is rather elongated and distorted (Table 3). ${ }^{16}$ Subsequently, the backbone folding continues as 310 -helical, in that two consecutive $\mathrm{C}_{10}$ structures are found, the $\mathrm{H}$-bond donors of which are the N9-H and N10-H groups, and the acceptors are the carbonyl oxygens of residues 6 and 7, respectively. The first of these latter two $\mathrm{C}_{10}$ structures is of type-III, whereas the second is close to type-I, ${ }^{14}$ as the backbone torsion angles of $\mathrm{Ala}(9)$, which occupies its $i+1$ corner position, lie in the 'bridge' region of the $\phi, \psi$ space $^{17}$ (Table 2). The following Aib(10) residue adopts torsion angles belonging to the left-handed helical region of the conformational map. As a result of the screw-sense inversion of $\operatorname{Aib}(10)$ relative to the 
preceding residues, the $\mathrm{N} 11-\mathrm{H}$ group, which would have been a donor to $\mathrm{O} 8$ if the backbone had continued a regular helical path, is located outside the helix. The N11-H group is H-bonded to the cocrystallized water molecule $\mathrm{O} 3 \mathrm{~W}$ that, in turn, is H-bonded as the donor to the O6 carbonyl oxygen, thus forming a water-mediated Schellman motif. ${ }^{18}$ The occurrence of such helix C-capping motif in peptides carrying an Aib residue at the penultimate position has been crystallographically documented in a number of cases, ${ }^{19}$ including a few examples in which the $i+5 \rightarrow i \mathrm{~N}-\mathrm{H} \ldots \mathrm{O}=\mathrm{C}$ intramolecular $\mathrm{H}$-bond $\left(\mathrm{C}_{16}\right.$ structure $)$ is mediated by the insertion of a cocrystallized solvent (methanol) molecule. ${ }^{20,21}$ The C-terminal Ala(11) residue, with $\phi$ and $\psi=-151.6(3)^{\circ}$ and $50.0(3)^{\circ}$, respectively, adopts a partially extended conformation.

The largely $\alpha$-helical folding of $\mathrm{Z}$-(L-Ala $)_{3}-(\mathrm{Aib}-\mathrm{L}-\mathrm{Ala})_{4}-\mathrm{OH}$, described above, is closely mirrored by the structures of two peptides of comparable length based on strictly alternating Aib-L-Ala residues. Specifically, in the dodecapeptide $p \mathrm{BrBz}-\left(\right.$ Aib-L-Ala) ${ }_{6}-\mathrm{OMe}, p \mathrm{BrBz}$ is para-bromobenzoyl, a $\mathrm{C}_{10}$ structure at the $\mathrm{N}$ terminus is encompassed within a $\mathrm{C}_{13}$ structure that is followed by seven additional $\mathrm{C}_{13}$ structures. Then, a $\mathrm{C}_{10}$ and a $\mathrm{C}_{16}$ structure generate the Schellman motif that acts as the C-cap of the $\alpha$-helix, with screw-sense inversion at the level of the penultimate $\mathrm{Aib}(11)$ residue. $^{22}$ Similarly, both the dihydrate $^{22}$ and the bis-dimethylsulfoxide solvate ${ }^{23}$ of the decapeptide $p \mathrm{BrBz}-(\text { Aib-L-Ala) })_{5}-\mathrm{OMe}$ display five consecutive $\mathrm{C}_{13}$ structures, followed by two $\mathrm{C}_{10}$ structures and a $\mathrm{C}_{16}$ structure, thus terminating again with a Schellman motif. It is worth noting that the corresponding backbone torsion angles of the four $(i+1 \div i+4)$, residues encompassed within the $\mathrm{H}$-bonded $\mathrm{C}_{16}$ structure, are identical (within $6^{\circ}$ ) in the three (Aib-Ala) $n$ structures. On the other hand, in our present undecapeptide, much larger deviations $\left(19^{\circ} \div 31^{\circ}\right)$ are observed for both $\phi$ and $\psi$ values of residue $i+3$ and the $\psi$ value of the screw-sense inverting residue $i+4$. In our view, these deviations would allow the replacement of the direct $i+5 \rightarrow i$

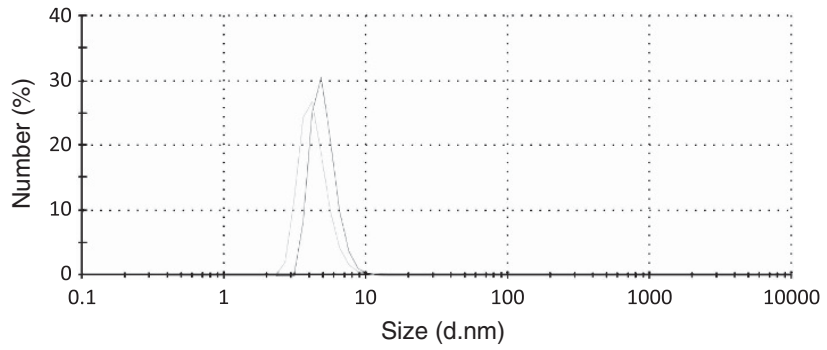

Figure 3 DLS size evaluation of Z-(Ala $)_{3}$-(Aib-L-Ala $)_{4}-\mathrm{OMe}$ in water. The two curves indicate two independent measurements. A full color version of this figure is available at Polymer Journal online.
$\mathrm{C}=\mathrm{O} \cdots \mathrm{H}-\mathrm{N}$ intramolecular $\mathrm{H}$-bond by the water-mediated $\mathrm{C}_{16}$ structure.

In the undecapeptide packing mode, the $\mathrm{N} 1-\mathrm{H}$ group is $\mathrm{H}$-bonded to the $\mathrm{O} 10$ carbonyl oxygen of a $(-1 / 2+\mathrm{x}, 1 / 2+\mathrm{y},-1+\mathrm{z})$ symmetry-related molecule, whereas the $\mathrm{N} 2-\mathrm{H}$ group is connected to the same acceptor through the insertion of the O1W water molecule. $\mathrm{O} 1 \mathrm{~W}$ is also $\mathrm{H}$-bonded, as the acceptor, to $\mathrm{O} 2 \mathrm{~W}$ that, in turn, is $\mathrm{H}$-bonded to the N3-H group. These either direct or watermediated interactions link peptide molecules head-to-tail along the $a b c$ direction. In addition, one direct and one water-mediated $\mathrm{H}$-bond laterally connect peptide molecules along the $b$ direction. Specifically, the C-terminal (carboxylic) O11T-H group is H-bonded to the O9 carbonyl oxygen of a $(\mathrm{x}, 1+\mathrm{y}, \mathrm{z})$ molecule, and the $\mathrm{O} 3 \mathrm{~W}$ water molecule (inserted between the $\mathrm{N} 11-\mathrm{H}$ and the $\mathrm{O} 6$ carbonyl in the Schellman motif) is H-bonded to O8 (symmetry: $\mathrm{x}, 1+\mathrm{y}, \mathrm{z}$ ). The remaining $\mathrm{H}$-bonding donor capability of $\mathrm{O} 1 \mathrm{~W}$ is satisfied by a $(5 / 2-x,-1 / 2+y, 2-z)$ symmetry equivalent of $O 11$, thus indirectly connecting molecules along the $a c$ direction, whereas $\mathrm{O} 2 \mathrm{~W}$ donates a H-bond to $\mathrm{O} 1$ (symmetry equivalence: $1 / 2+\mathrm{x}, 1 / 2+\mathrm{y}, 1+\mathrm{z}$ ).

\section{Morphology of the peptide aggregates in water}

To assess the presence of molecular aggregates, DLS is a fast and reliable technique. According to our measurements (data not shown), all water-soluble Aib/Ala peptides previously investigated ${ }^{1,2}$ do form large aggregates in water, provided an appropriate concentration (critical aggregate concentration) is achieved. The average dimensions of these aggregates range from 20 to $100 \mathrm{~nm}$. In this preliminary report, we decided to focus on $\mathrm{Z}$-(L-Ala) ${ }_{3}$-(Aib-L-Ala) $)_{4}$-OMe in view of its relevant size and applications. ${ }^{1}$ DLS measurements of this peptide in aqueous solution (Figure 3) clearly indicate the occurrence of large aggregates of up to $100 \mathrm{~nm}$ hydrodynamic radius. These measurements, repeated several times on freshly prepared peptide solutions, were completely reproducible. Interestingly, when our undecapeptide was dissolved in methanol, the DLS analysis detected structures about 10 times smaller (2-10 $\mathrm{nm}$ in hydrodynamic radius), consistent with the presence of isolated peptide molecules and small aggregates. It is worth reminding here that the N-to-C length of an $\alpha$-helical peptide of 11 residues does not exceed $2 \mathrm{~nm}$. Therefore, these data clearly indicate that large, self-assembled, peptide bodies do form in water.

To further evaluate the size and shape of our aggregates, aqueous solutions of $\mathrm{Z}$-( $\mathrm{L}-\mathrm{Ala})_{3}$-(Aib-L-Ala) $)_{4}$-OMe were investigated also by means of the TEM technique with uranyl acetate as staining agent. Spherical assemblies were observed (Figure 4), comparable in size to those revealed by DLS (Figure 4b). Smaller spherical aggregates (about
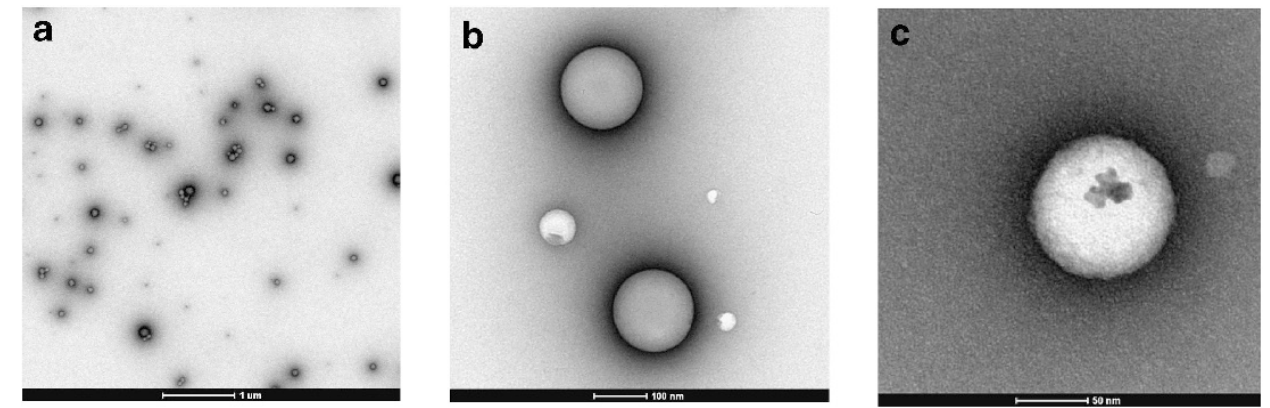

Figure 4 TEM images of Z-(Ala $)_{3}-(\mathrm{Aib}-\mathrm{L}-\mathrm{Ala})_{4}-\mathrm{OMe}$ from an aqueous solution. The sample was stained negatively with uranyl acetate. The scale bars represent 1000 (a), 100 (b) and $50 \mathrm{~nm}(\mathbf{c})$, respectively. 

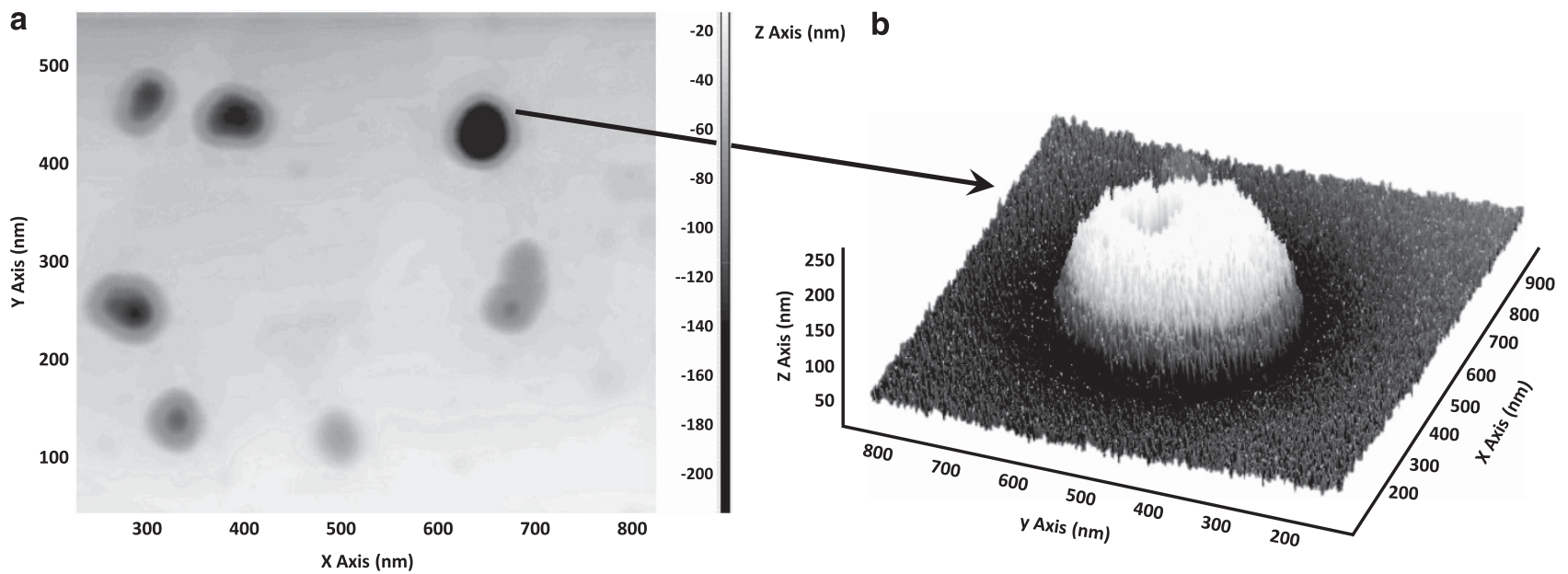

Figure 5 Atomic force microscopy images of the Z-(Ala) $)_{3}$ (Aib-L-Ala) $)_{4}$-OMe aggregates formed in aqueous solution. The $x$ axis of panel a spans about $0.6 \mu \mathrm{m}$. In panel $\mathbf{b}$, the three-dimensional structure of an aggregate is reported.
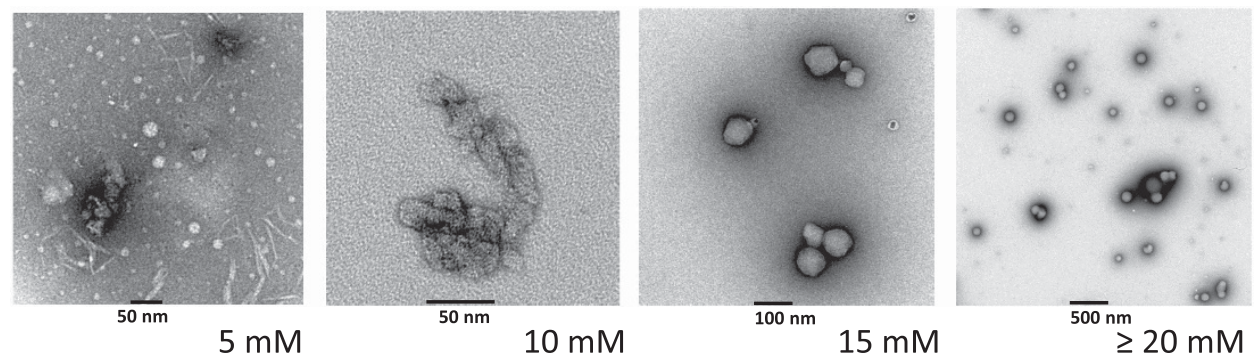

Figure 6 TEM images of Z-(Ala) $3_{3}$-(Aib-L-Ala $)_{4}-\mathrm{OMe}$ at different concentrations from an aqueous solution. The sample was stained negatively with urany acetate. The scale bars represent $50(5 \mathrm{~mm}), 50(10 \mathrm{~mm}), 100(15 \mathrm{~mm})$ and $500 \mathrm{~nm}$ ( $\geqslant 20 \mathrm{~mm})$, respectively.

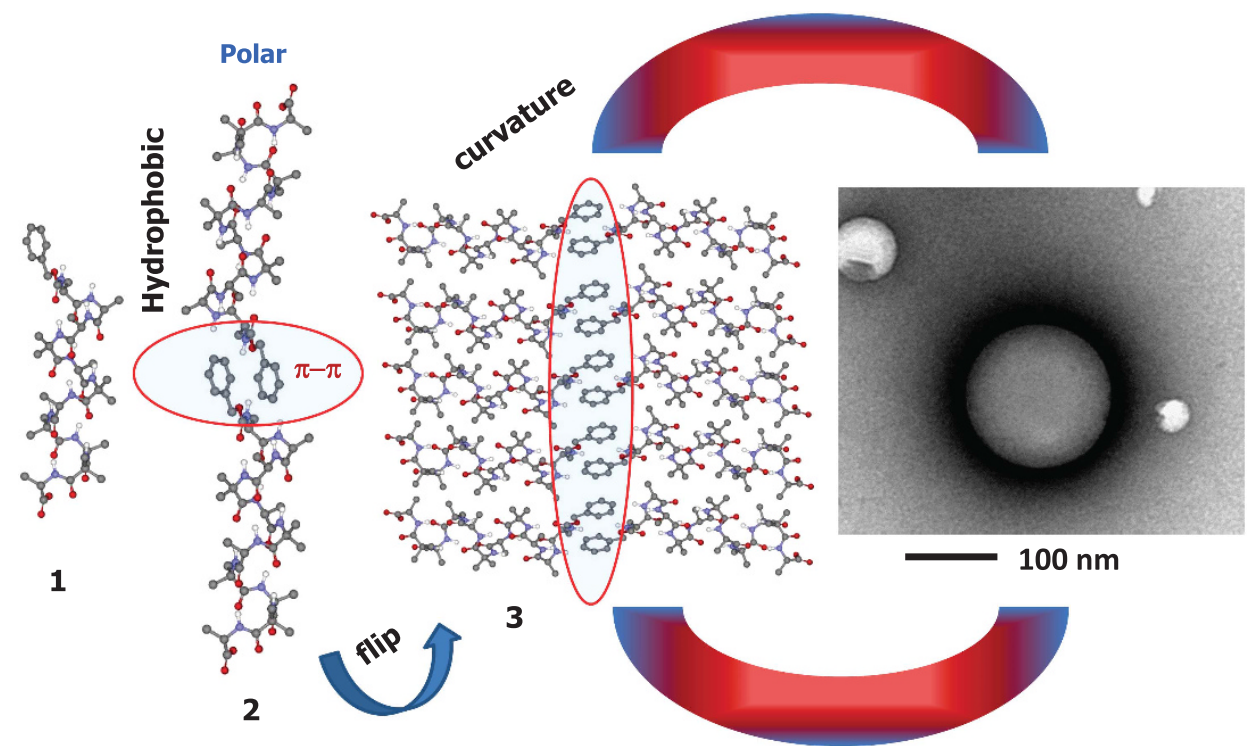

Figure 7 Tentative explanation of the mechanism by which Z-(Ala) $)_{3}-(\mathrm{Aib}-\mathrm{L}-\mathrm{Ala})_{4}-\mathrm{OMe}$ forms spherical microaggregates in water solution.

$10 \mathrm{~nm}$ ) are also present (Figure 4a). They possibly represent the initial steps of a pathway leading to the larger aggregates.

The atomic force microscopy analysis of the same peptide sample, deposited on a mica substrate, confirms the size (about $100 \mathrm{~nm}$,
Figure 5a) and, most importantly, the spherical nature (Figure 5b) of these peptide aggregates.

The critical aggregate concentration of $\mathrm{Z}-(\mathrm{Ala})_{3}-(\mathrm{Aib}-\mathrm{L}-\mathrm{Ala})_{4}-\mathrm{OMe}$ was estimated by means of TEM measurements. Peptide solutions 
from 5 to $>20 \mathrm{~mm}$ concentrations were submitted to TEM analysis. The images reported in Figure 6 clearly show that regular, spherical aggregates are observed only for concentrations $>15 \mathrm{~mm}$.

A tentative explanation for the formation of $\mathrm{Z}$-(Ala $)_{3}$-(Aib-L-Ala $)_{4^{-}}$ OMe microstructures in water solution is depicted in Figure 7. Above critical aggregate concentration, single monomers (Figures 1 and 7) might 'dimerize' (Figures 2 and 7) through noncovalent interactions ( $\pi-\pi$ stacking) of the $\mathrm{Z}$ aromatic moieties. These $\pi-\pi$ interactions could further extend to generate a network (Figures 3 and 7) that, ultimately, might arrange into a spherical aggregate to minimize the overall solvation energy.

\section{Encapsulation experiments}

We also checked the ability of the $\mathrm{Z}$-(Ala) $)_{3}$ (Aib-L-Ala $)_{4}$-OMe aggregates to encapsulate other molecules. As guest, we chose the water-soluble, peptide-coated $\mathrm{Au}$ nanoparticles AuNps11, ${ }^{1}$ characterized by an average diameter of $6 \mathrm{~nm}(2 \mathrm{~nm}$ the $\mathrm{Au}$ core and $2+2 \mathrm{~nm}$ the helical peptide capping layer). A dark, red-colored, water solution of AuNps11 was added to a clear and colorless water solution of $\mathrm{Z}$-(Ala) $)_{3}$-(Aib-L-Ala) $)_{4}$-OMe. To remove the free, not
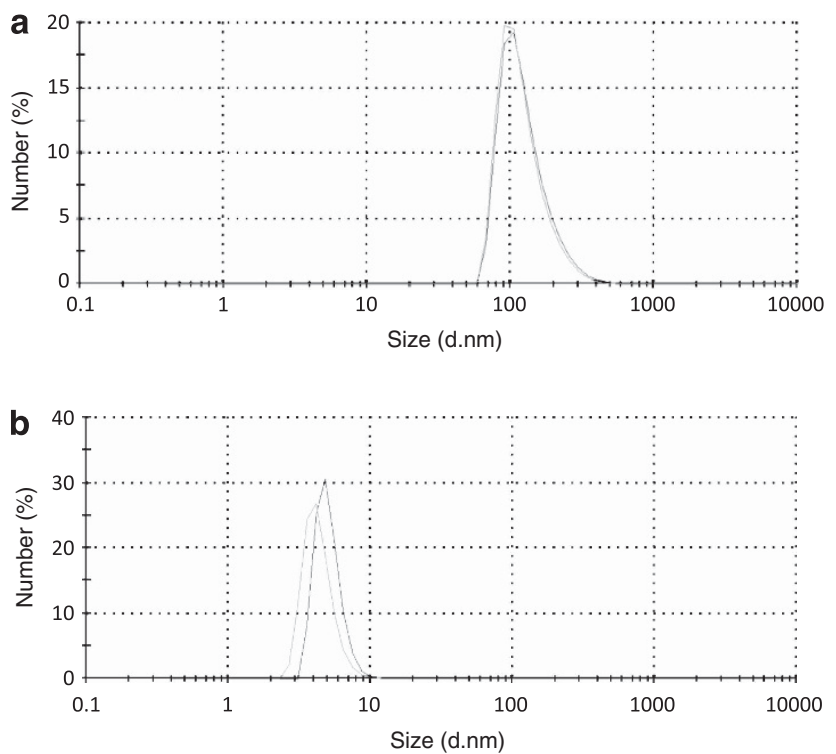

Figure 8 DLS patterns for Z-(Ala) $)_{3}$ (Aib-L-Ala) $)_{4}-\mathrm{OMe} / \mathrm{AuNps} 11$ aggregates (a) and AuNps11 alone (b) in water. A full color version of this figure is available at Polymer Journal online. encapsulated, AuNps11, the mixture was applied to a size-exclusion Superdex 75 preparative column (3000-70 000 Da; GE Healthcare Life Sciences, Piscataway, NJ, USA). At the expected retention time, one major peak was observed, isolated and subsequently analyzed by means of DLS and TEM. Interestingly, the solution corresponding to this peak was colored, which indicates the presence of AuNps11. DLS analysis of this fraction revealed the presence of aggregates with hydrodynamic radii of about $100 \mathrm{~nm}$ (Figure 8a). As a control, the same technique gave a one order of magnitude smaller size for AuNps11 alone (Figure 8b).

The TEM images of the same samples (Figure 9) are in agreement with the DLS analysis (Figure 8). In these TEM experiments, the uranyl acetate staining was not needed, as the Au atoms of the encapsulated AuNps11 allowed an easy detection. Figure 7a shows a TEM image of the Z-(Ala) $)_{3}$-(Aib-L-Ala) $)_{4}$-OMe/AuNps11 mixture, before the size-exclusion chromatography separation. It is quite clear that several AuNps11 have been incorporated into our undecapeptide aggregates, thus permitting their detection. The size (about $100 \mathrm{~nm}$ ) of the two large bodies of Figure 9a is in agreement with the values obtained from the DLS measurements (Figure 8a). On the other hand, the numerous small dark spots, enlarged in the inset of Figure 9a, are ascribed to free, not encapsulated AuNps11, as their size $(2 \mathrm{~nm})$ matches that of the AuNps11 metal core. ${ }^{1}$ After size-exclusion chromatography, the small spots of free AuNps11 disappear (Figure 9b) as clearly seen in the expansion (Figure 9c). Under these conditions, only the large peptide aggregates, with the AuNps11 encapsulated, are observed.

\section{Aggregate constituents}

Given the formation in water of large, spherical, self-assembled aggregates for $\mathrm{Z}$-(L-Ala) $)_{3}$ (Aib-L-Ala) ${ }_{4}-\mathrm{OMe}^{1}$ and related, shorter peptides $^{2}$ for granted, the main open issue remaining is what these aggregates are made of: just peptides or solvated (hydrated) peptides?

Micelles and vesicles are two well-known assemblies occurring in nature. For the formation of both of them, amphiphilic molecules are required. Our terminally protected Aib/Ala peptides do not possess charges or any highly polar groups, with the exception of the non intramolecularly $\mathrm{H}$-bonded amide $\mathrm{N}-\mathrm{H}$ and $\mathrm{C}=\mathrm{O}$ groups at the $\mathrm{N}$ and $\mathrm{C}$ terminus, respectively. Interestingly, in the undecapeptide crystal structure discussed above, the Schellman motif involves four free carbonyl oxygens, rather than the three found in a regular $\alpha$-helix. In addition, the Schellman motif induces a kink on the C-terminal segment of the peptide helix. These two features, together with the aromatic $\pi-\pi$ interactions described above, might be relevant for the formation of the supramolecular, self-assembled structures observed
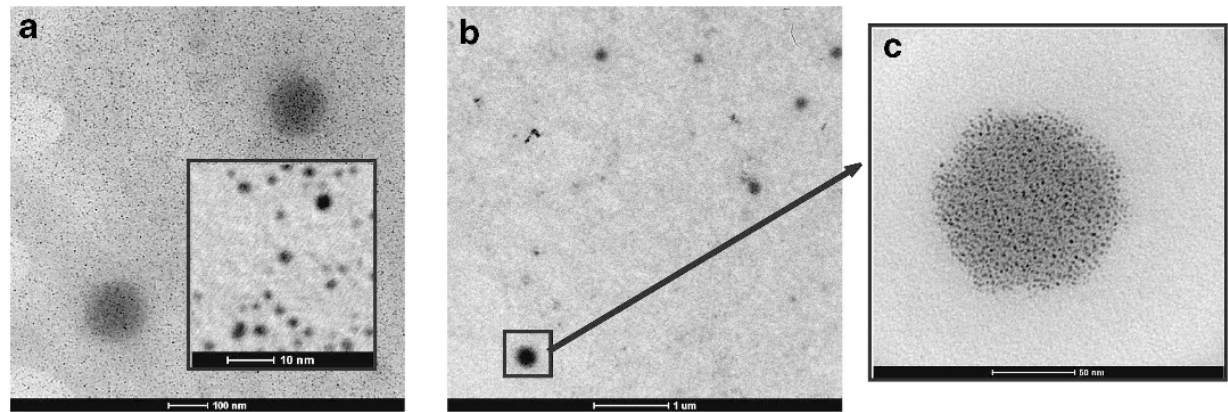

Figure 9 TEM images from aqueous solutions containing Z-(Ala) ${ }_{3}$-(Aib-L-Ala) ${ }_{4}-\mathrm{OMe}$ and AuNps 11 before (a) and after (b, c) size-exclusion chromatography. No staining with uranyl acetate was performed. The scale bars represent 100 (a), 10 (a, inset), 1000 (b) and $50 \mathrm{~nm}$ (c), respectively. 
by TEM and DLS. In addition, the role of the helix dipole moment should also be considered. Indeed, a few years ago Kimura and coworkers suggested the fascinating concept according to which molecules with a large dipole moment are intrinsically hydrophilic. ${ }^{24}$

In any case, micellar aggregates of $\mathrm{Z}$-(L-Ala $)_{3}$-(Aib-L-Ala $)_{4}-\mathrm{OMe}$ would have a diameter not larger than $5 \mathrm{~nm}$, that is, approximately twice the length of the peptide helix (about $2 \mathrm{~nm}$ ). Conversely, the aggregates observed by DLS and TEM exhibit a diameter about 10 times larger. Then, the likely formation of vesicles should be taken into account. In this event, our aggregates could contain water molecules in their interior. To ascertain this possibility, we are currently planning the incorporation of appropriate spectroscopic probes $^{25,26}$ into our self-assembled aggregates.

\section{CONCLUSIONS}

The main contribution of this work stands in the discovery that a series of Aib/Ala peptides, lacking any charge or polar group, dissolve in water through the formation of self-assembled superstructures. These aggregates are larger than a typical micelle, although it is not clear yet if they form vesicles or a different type of supramolecular structure. Our contention, supported by X-ray diffraction data, is that a hydrophilic side (the $\mathrm{N}$ and/or the $\mathrm{C}$ terminus and/or a face of the helix) of the peptide has to be located on the outer layer of these aggregates. Additional syntheses and experiments are currently in progress in our laboratory to understand the molecular composition of these large, spherical structures. We are confident that our efforts will add a new tool to the number of possible applications envisaged for peptide self-assembled aggregates. ${ }^{26-31}$

\section{ACKNOWLEDGEMENTS}

AM and FF gratefully acknowledge the University of Padova (PRAT 2011) and the Italian Ministry of Research (PRIN 2010-2011, 2010NRREPL_003) for financial support. MC is grateful to Professor A Dolmella (Department of Pharmaceutical Sciences, University of Padova) for granting access to the Gemini diffractometer and for his help with X-ray data collection and processing. Financial support for the acquisition of the Agilent Gemini diffractometer was provided by the University of Padova through the 2008 'Scientific Equipment for Research' initiative.

1 Rio-Echevarria, I. M., Tavano, R., Causin, V., Papini, E., Mancin, F. \& Moretto, A Water-soluble peptide-coated nanoparticles: control of the helix structure and enhanced differential binding to immune cells. J. Am. Chem. Soc. 133, 8-11 (2011).

2 Longo, E., Moretto, A., Formaggio, F. \& Toniolo, C. The critical main-chain length for helix formation in water: determined in a peptide series with alternating Aib and Ala residues exclusively and detected with ECD spectroscopy. Chirality 23, 756-760 (2011).

3 Vijayakumar, E. K. S. \& Balaram, P. Stereochemistry of $\alpha$-aminoisobutyric acid peptides in solution: helical conformations of protected decapeptides with repeating Aib-L-Ala and Aib-L-Val sequences. Biopolymers 22, 2133-2140 (1983).

4 Kennedy, D. F., Crisma, M., Toniolo, C. \& Chapman, D. Studies of peptides forming $3_{10^{-}}$and $\alpha$-helices and $\beta$-bend ribbon structures in organic solution and in mode membranes by fourier transform infrared spectroscopy. Biochemistry 30, 6541-6548 (1991)
5 Otoda, K., Kimura, S. \& Imanishi, Y. Orientation and aggregation of hydrophobic helical peptides in phospholipid bilayer membranes. Biochim. Biophys. Acta 1150, 1-8 (1993).

6 Arikuma, Y., Nakayama, H., Morita, T. \& Kimura, S. Electron hopping over $100 \AA$ along an $\alpha$-helix. Angew. Chem. Int. Ed. 49, 1800-1804 (2010).

7 Arikuma, Y., Nakayama, H., Morita, T. \& Kimura, S. Ultra-long-range electron transfer through a self-assembled monolayer of gold composed of $120-\AA$-long $\alpha$-helices. Langmuir 27, 1530-1535 (2011).

8 Burla, M. C., Camalli, M., Carrozzini, B., Cascarano, G. L., Giacovazzo, C. Polidori, G. \& Spagna, R. SIR2002: the program. J. Appl. Crystallogr. 36, 1103 (2003).

9 Sheldrick, G. M. A short history of SHELX. Acta Crystallogr. A 64, 112-122 (2008).

10 Manning, M. C. \& Woody, R. W. Theoretical CD studies of polypeptide helices: examination of important electronic and geometric factors. Biopolymers 31, 569-586 (1991).

11 Toniolo, C., Polese, A., Formaggio, F., Crisma, M. \& Kamphuis, J. Circular dichroism spectrum of a peptide 310-helix. J. Am. Chem. Soc. 118, 2744-2745 (1996).

12 Toniolo, C. Intramolecularly hydrogen-bonded peptide conformations. CRC Crit. Rev. Biochem. 9, 1-44 (1980)

13 Crisma, M., Formaggio, F., Moretto, A. \& Toniolo, C. Peptide Helices Based on $\alpha$-Amino Acids. Biopolymers (Pept. Sci.) 84, 3-12 (2006)

14 Venkatachalam, C. M. Conformation of a system of three-linked peptide units. Biopolymers 6, 1425-1436 (1968).

15 Taylor, R., Kennard, O. \& Versichel, W. Geometry of the nitrogen-hydrogen...oxygencarbon ( $\mathrm{N}-\mathrm{H} \ldots \mathrm{O}: \mathrm{C}$ ) hydrogen bond. 2. three-center (bifurcated) and four-center (trifurcated) bonds. J. Am. Chem. Soc. 106, 244-248 (1984).

16 Görbitz, C. H. Hydrogen-bond distances and angles in the structures of amino acids and peptides. Acta Crystallogr. B45, 390-395 (1989).

17 Zimmerman, S. S., Pottle, M. S., Némethy, G. \& Scheraga, H. A. Conformational analysis of the 20 naturally occurring amino acid residues using ECEPP. Macromolecules 10, 1-9 (1977).

18 Schellman, C. in Protein Folding. Jaenicke, R. (ed.) 53-61 (Elsevier/North Holland Biochemical Press, Amsterdam, 1980).

19 Datta, S., Shamala, N., Banerjee, A., Pramanik, A., Bhattacharja, S. \& Balaram, P. Characterization of helix terminating Schellman motifs in peptides. Crystal structure and nuclear Overhauser effect analysis of a synthetic heptapeptide helix. J. Am. Chem. Soc. 119, 9246-9251 (1997).

20 Karle, I. L., Banerjee, A., Bhattacharjya, S. \& Balaram, P. Solid state and solution conformations of a helical peptide with a central Gly-Gly segment. Biopolymers $\mathbf{3 8}$, 515-526 (1996).

21 Banerjee, A., Raghothama, S. R., Karle, I. L. \& Balaram, P. Ambidextrous molecules: cylindrical peptide structures formed by fusing left and right handed helices. Biopolymers 39, 279-285 (1996).

22 Benedetti, E., Di Blasio, B., Pavone, V., Pedone, C., Santini, A., Bavoso, A., Toniolo, C. Crisma, M. \& Sartore, L. Linear oligopeptides. Part 227. X-ray crystal and molecular structures of two $\alpha$-helix-forming (Aib-L-Ala) sequential oligopeptides, pBrBz-(Aib-L-Ala) $)_{5}-\mathrm{OMe}$ and pBrBz-(Aib-L-Ala) ${ }_{6}-\mathrm{OMe}$. J. Chem. Soc. Perkin Trans. 2 1829-1837 (1990).

23 Di Blasio, B., Pavone, V., Saviano, M., Fattorusso, R., Pedone, C., Benedetti, E. Crisma, M. \& Toniolo, C. A second polymorph of a helical decapeptide. Pept. Res. 7, 55-59 (1994).

24 Fukuda, M., Sugiyama, J., Morita, T. \& Kimura, S. Fully hydrophobic artificial protein but water dispersible due to large dipole. Polym. J. 38, 381-386 (2006).

25 Tovar, J. D., Claussen, R. C. \& Stupp, S. I. Probing the interior of peptide amphiphile supramolecular aggregates. J. Am. Chem. Soc. 127, 7337-7345 (2005).

26 Tanisaka, H., Kizaka-Kondoh, S., Makino, A., Tanaka, S., Hiraoka, M. \& Kimura, S. Near-infrared fluorescent labeled peptosome for application to cancer imaging. Bioconjugate Chem. 19, 109-117 (2008).

27 Zhang, S. Fabrication of novel biomaterials through molecular self-assembly. Nature Biotechnol. 21, 1171-1178 (2003).

28 Colombo, G., Soto, S. \& Gazit, E. Peptide self-assembly at the nanoscale: a challenging target for computational and experimental biotechnology. Trends Biotechnol. 25, 211-218 (2007)

29 Zhao, X., Pan, F. \& Lu, J. R. Recent development of peptide self-assembly. Prog. Nat. Sci. 18, 653-660 (2008).

30 Cui, H., Webber, M. J. \& Stupp, S. I. Self-assembly of peptides amphiphiles: from molecules to nanostructures to biomaterials. Biopolymers 94, 1-18 (2010).

31 Hamley, I. W. Self-assembly of amphiphilic peptides. Soft Matter 7, 4122-4138 (2011). 